\title{
Parameter Optimization of Wire EDM for EN 24 Alloy Steel
}

\author{
$(\text { Mr. Aashish })^{1},(\text { Mr. Ashok Rana })^{2}$ \\ ${ }^{I}$ (M.Tech,Mechanical Engineering department, Ambala College of Engineering and Applied Research Mithapur \\ /Kurukshetra university, Kurukshetra, Haryana, India) \\ ${ }^{2}$ (Professor,Mechanical department, Ambala College of Engineering and Applied Research Mithapur \\ /Kurukshetra university, Kurukshetra, Haryana, India)
}

\begin{abstract}
Electrical discharge machining (EDM) is one of the earliest non-traditional machining processes.EDM process is based on thermoelectric energy between the work piece and an electrode. A pulse discharge occurs in a small gap between the work piece and the electrode and removes the unwanted material from the parent metal through melting and vaporizing. This study presents a methodology for evaluation, ranking and selection of parameters of Wire Electric Discharge Machine by using Taguchi's approach for EN24 Alloy Steel.EN24 is a high quality, high tensile, alloy steel and combines high tensile strength, shock resistance, good ductility and resistance to wear. But the machining of this material is difficult with the conventional machining process. So in this work wire EDM process is proposed for the machining of EN-24 alloy steel. The output parameters like material removal rate and surface roughness of the material is affected by large no of input variables like current voltage pulse on time and pulse off time etc. Hence a suitable selection of input variables for the wire electrical discharge machining (WEDM) process is required. This work proposes optimal parameter setting using Taguchi's parameter design. The effect of each control factor on the performance measure is studied individually using the plots of signal to noise ratio. The study demonstrates that the WEDM process parameters can be adjusted so as to achieve better metal removal rate and surface finish. The effects of all input parameters and output responses analyzed using the analysis of variance (ANOVA)
\end{abstract}

Keywords: Wire electric discharge machine, EN-24(Low Alloy Steel),

\section{Introduction}

Wire electrical discharge machining (WEDM) is among the more widely known and applied nontraditional machining processes in industry today. In this procedure, improvements to the process mechanism and control have rapidly been taking place. WEDM can machine harder, they are higher strength, corrosive and wear-resistant, and difficult-to machine materials. With WEDM, it is also possible to machine complicated shapes that cannot otherwise be achieved using traditional machining processes, such as turning, milling, and grinding

EN24 is a high quality, high tensile, alloy steel and combines high tensile strength, shock resistance, good ductility and resistance to wear. EN24 is most suitable for the manufacture of parts such as heavy-duty axles and shafts, gears, bolts and studs. EN24 is capable of retaining good impact values at low temperatures. The chemical composition of the material is below in table.

Table1. Chemical Composition of EN-24

\begin{tabular}{|l|l|l|l|l|l|l|l|l|l|}
\hline $\mathrm{C} \%$ & $\mathrm{Mn} \%$ & $\mathrm{P} \%$ & $\mathrm{~S} \%$ & $\mathrm{Si} \%$ & $\mathrm{Cu} \%$ & $\mathrm{Ni} \%$ & $\mathrm{Cr} \%$ & $\mathrm{~V} \%$ & $\mathrm{Mo} \%$ \\
\hline 0.3795 & 0.5717 & 0.04650 & 0.04961 & 0.2357 & 0.1104 & 1.26 & 1.066 & 0.0198 & 0.2177 \\
\hline
\end{tabular}

\section{Experimental Setup}

The machine Wire EDM brand Elektra model number ELCUT 234 situated at the CITCO Chandigarh. The EN24 case hardening steel round plate of diameter $70 \mathrm{~mm}$ and thickness $10 \mathrm{~mm}$ is mounted on the ELCUT 234 WEDM machine tool and specimens of $10 \mathrm{~mm}$ size are cut

Table 2: Levels of Input Machining Parameters

\begin{tabular}{|l|l|l|l|l|}
\hline \multirow{2}{*}{ S.NO. } & \multirow{2}{*}{ INPUT PARMETERS } & LEVEL & 2 & 3 \\
\cline { 3 - 5 } & & 1 & 6 & 8 \\
\hline 1. & Current $(\mathrm{Ip})$ & 4 & 65 & 70 \\
\hline 2. & Voltage $(\mathrm{V})$ & 60 & 5 & 7 \\
\hline 3. & Pulse on time $\left(\mathrm{T}_{\text {on }}\right)$ & 3 & 4 & 6 \\
\hline 4. & Pulse off time $\left(\mathrm{T}_{\text {off }}\right)$ & 2 & 4 & 7 \\
\hline
\end{tabular}

Taguchis method used for the experiment with the design of experiment L9 orthogonal Array. Table 3 show the orthogonal array with the different input variables 
Table3: L 9 Orthogonal Array with input parameters

\begin{tabular}{|l|l|l|l|l|}
\hline \multirow{2}{*}{ Sr. No. } & \multicolumn{4}{|l|}{ Design of Experiments with orthogonal Array ( $\mathrm{L}_{9}$ orthogonal Array) } \\
\cline { 2 - 5 } & Current $(\mathrm{Ip})$ & Voltage $(\mathrm{V})$ & Pulse on time $\left(\mathrm{T}_{\text {on }}\right)$ & Pulse off time $\left(\mathrm{T}_{\text {off }}\right)$ \\
\hline 1 & 4 & 60 & 3 & 2 \\
\hline 2 & 4 & 65 & 5 & 4 \\
\hline 3 & 4 & 70 & 7 & 6 \\
\hline 4 & 6 & 60 & 5 & 6 \\
\hline 5 & 6 & 65 & 7 & 2 \\
\hline 6 & 6 & 70 & 3 & 4 \\
\hline 7 & 8 & 60 & 7 & 4 \\
\hline 8 & 8 & 65 & 3 & 6 \\
\hline 9 & 8 & 70 & 5 & 2 \\
\hline
\end{tabular}

III. Results and Discussions

Total 9 experiments were conducted for the $\mathrm{L}_{9}$ experimental design. The weight of each experiment were repeated three times it means for every experiment there were three values of MRR as shown in the Table 4. So the analysis is based on the three responses of MRR. For the results of MRR, firstly $\mathrm{S} / \mathrm{N}$ ratio is to be calculated. The material MRR is expressed as the ratio of the difference of weight of the work piece before and after machining to the machining time. It is being measured in terms of $\mathrm{mg} / \mathrm{min}$.

$\operatorname{MRR}=\left(\mathrm{M}_{\mathrm{i}}-\mathrm{M}_{\mathrm{f}}\right) / \mathrm{t}$

Table 3.1: Observation during Machining Of En 24 Alloy Steel

\begin{tabular}{|c|c|c|c|c|c|c|c|c|c|}
\hline \multirow[t]{2}{*}{$\begin{array}{l}\text { Sr. } \\
\text { No. }\end{array}$} & \multirow[t]{2}{*}{ Current (Ip) } & \multirow[t]{2}{*}{ Voltage (V) } & \multirow[t]{2}{*}{$\begin{array}{l}\text { Pulse on } \\
\text { time }\left(\mathrm{T}_{\text {on }}\right)\end{array}$} & \multirow[t]{2}{*}{$\begin{array}{l}\text { Pulse off } \\
\text { time }\left(\mathrm{T}_{\text {off }}\right)\end{array}$} & \multicolumn{3}{|c|}{$\begin{array}{l}\text { Work piece wt. } \\
\text { (grams) }\end{array}$} & \multirow[t]{2}{*}{ S/N Ratio } & \multirow[t]{2}{*}{$\begin{array}{l}\text { MEAN } \\
\text { Ratio }\end{array}$} \\
\hline & & & & & M1 & M2 & M3 & & \\
\hline 1 & 4 & 60 & 3 & 2 & 0.20 & 0.21 & 0.19 & -14.0012 & 0.20 \\
\hline 2 & 4 & 65 & 5 & 4 & 0.23 & 0.21 & 0.19 & -13.6349 & 0.21 \\
\hline 3 & 4 & 70 & 7 & 6 & 0.12 & 0.16 & 0.14 & -17.2571 & 0.14 \\
\hline 4 & 6 & 60 & 5 & 6 & 0.18 & 0.19 & 0.17 & -14.9214 & 0.18 \\
\hline 5 & 6 & 65 & 7 & 2 & 0.27 & 0.26 & 0.25 & -11.7134 & 0.25 \\
\hline 6 & 6 & 70 & 3 & 4 & 0.31 & 0.33 & 0.32 & -9.9055 & 0.32 \\
\hline 7 & 8 & 60 & 7 & 4 & 0.44 & 0.43 & 0.45 & -7.1354 & 0.44 \\
\hline 8 & 8 & 65 & 3 & 6 & 0.46 & 0.45 & 0.44 & -6.9400 & 0.45 \\
\hline 9 & 8 & 70 & 5 & 2 & 0.47 & 0.49 & 0.48 & -6.3789 & 0.48 \\
\hline
\end{tabular}

Taguchi recommends analyzing data using the $\mathrm{S} / \mathrm{N}$ ratio. It is used to select the optimum parameters. According to Taguchi method, S/N ratio is the ratio of "Signal" representing desirable value, i.e. mean of output characteristics and the "noise" representing the undesirable value i.e., squared deviation of the output characteristics. It is denoted by $\eta$ and the unit is $\mathrm{dB}$. The $\mathrm{S} / \mathrm{N}$ ratio is used to measure quality characteristic and it is also used to measure significant welding parameters. The $\mathrm{S} / \mathrm{N}$ ratio calculates the mean (signal) and the standard deviation (noise) of process,

Table 3.2: Response Table for Signal to Noise Ratios (Larger is Better)

\begin{tabular}{|l|l|l|l|l|}
\hline Level & $\begin{array}{l}\text { Current } \\
(\mathrm{A})\end{array}$ & $\begin{array}{l}\text { Voltage } \\
(\mathrm{B})\end{array}$ & $\begin{array}{l}\text { Pulse on time } \\
(\mathrm{C})\end{array}$ & $\begin{array}{l}\text { Pulse off time } \\
(\mathrm{D})\end{array}$ \\
\hline 1 & -14.964 & -12.019 & -10.262 & -10.698 \\
\hline 2 & -12.180 & -10.763 & -11.645 & -10.225 \\
\hline 3 & -6.818 & -11.181 & -12.035 & -13.040 \\
\hline Delta & 8.146 & 1.257 & 1.735 & 2.814 \\
\hline Rank & 1 & 4 & 3 & 2 \\
\hline
\end{tabular}

Table 3.3: Response Table for Mean (Larger is Better)

\begin{tabular}{|l|l|l|l|l|}
\hline Level & $\begin{array}{l}\text { Current } \\
(\mathrm{A})\end{array}$ & $\begin{array}{l}\text { Voltage } \\
(\mathrm{B})\end{array}$ & $\begin{array}{l}\text { Pulse on time } \\
(\mathrm{C})\end{array}$ & $\begin{array}{l}\text { Pulse off time } \\
(\mathrm{D})\end{array}$ \\
\hline 1 & 0.1833 & 0.2733 & 0.3233 & 0.3133 \\
\hline 2 & 0.2533 & 0.3067 & 0.2900 & 0.3233 \\
\hline 3 & 0.4567 & 0.3133 & 0.2800 & 0.2567 \\
\hline Delta & 0.2733 & 0.0400 & 0.0433 & 0.0667 \\
\hline Rank & 1 & 4 & 3 & 2 \\
\hline
\end{tabular}

Table 3.3 shows the major factor which affects the MRR. It is clearly shows in the response table for MRR that Current is ranked one; Pulse off Time is ranked second, Pulse off time third and voltage is fourth.Now these values of $\mathrm{S} / \mathrm{N}$ ratio and Mean are plotted in the shape of a graph which will tell individual parameter and its effect. 

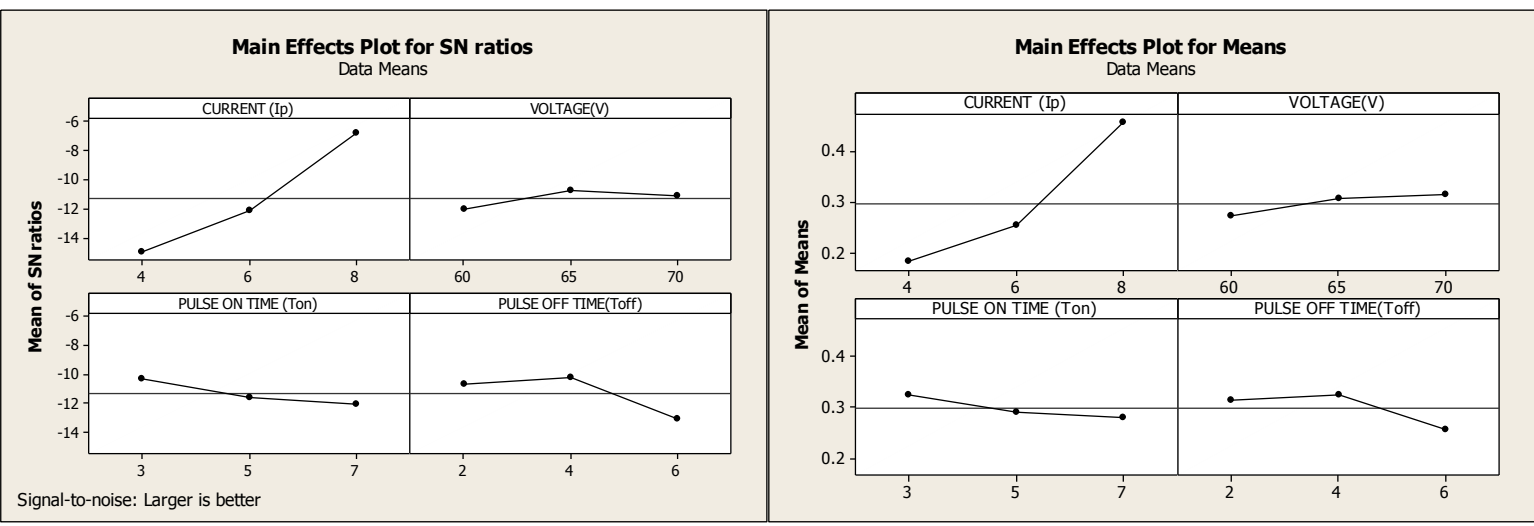

Figure 3.1: main effects plot for mean and $\mathrm{S} / \mathrm{N}$ ratio

It can be seen by the figure 3.1 clearly that the value of material removal rate is increases sharply for the Current as their level increases because the current has main effect on the material removal rate. The discharge energy increases with increasing the value of the current and larger discharge energy produces a larger crater. This is the main reason that the material removal rate is increasing as the value of the current is increasing. The value of MRR for voltage first increases then decreases, pulse on time sharply decreases and pulse off time increases and then decrease as their value increases. As the pulse off time decreases, the number of discharges within a given period becomes more which leads to a higher cutting rate

\section{Analysis of SR}

During the conduction of all the 9 experiments with different set of input parameters After the completion of all the experiments the observation reading of the Surface Roughness were filled in orthogonal array as shown in table 3.4. Where SR1, SR2 \& SR3 are the Surface Roughness after machining of work piece. After getting the observation after machining of work piece we get the SR from the surface roughness measuring instrument. Calculation of the values of $s / n$ ratio and mean with the help of Taughi method and these values shows in the average table

Table 3.4: Observation after Machining of En 24 Alloy Steel

\begin{tabular}{|c|c|c|c|c|c|c|c|c|c|}
\hline \multirow[t]{2}{*}{$\begin{array}{l}\text { Sr. } \\
\text { No. }\end{array}$} & \multirow[t]{2}{*}{ Current (Ip) } & \multirow[t]{2}{*}{ Voltage (V) } & \multirow[t]{2}{*}{$\begin{array}{l}\text { Pulse on } \\
\text { time }\left(\mathrm{T}_{\text {on }}\right)\end{array}$} & \multirow[t]{2}{*}{$\begin{array}{l}\text { Pulse off } \\
\text { time }\left(\mathrm{T}_{\text {off }}\right)\end{array}$} & \multicolumn{3}{|c|}{$\begin{array}{l}\text { Work piece wt. } \\
\text { (grams) }\end{array}$} & \multirow[t]{2}{*}{ S/N Ratio } & \multirow[t]{2}{*}{$\begin{array}{l}\text { MEAN } \\
\text { Ratio }\end{array}$} \\
\hline & & & & & SR1 & SR2 & SR3 & & \\
\hline 1 & 4 & 60 & 3 & 2 & 2.150 & 2.234 & 2.807 & -7.6673 & 2.39700 \\
\hline 2 & 4 & 65 & 5 & 4 & 2.768 & 1.915 & 2.533 & -7.7196 & 2.40533 \\
\hline 3 & 4 & 70 & 7 & 6 & 2.143 & 2.371 & 2.833 & -7.8390 & 2.44900 \\
\hline 4 & 6 & 60 & 5 & 6 & 2.621 & 3.281 & 2.103 & -8.6643 & 2.66833 \\
\hline 5 & 6 & 65 & 7 & 2 & 2.032 & 2.468 & 1.511 & -6.1990 & 2.00367 \\
\hline 6 & 6 & 70 & 3 & 4 & 2.189 & 2.221 & 2.012 & -6.6190 & 2.14067 \\
\hline 7 & 8 & 60 & 7 & 4 & 5.784 & 5.602 & 4.403 & -14.4831 & 5.26300 \\
\hline 8 & 8 & 65 & 3 & 6 & 6.828 & 4.586 & 4.873 & -14.8382 & 5.42900 \\
\hline 9 & 8 & 70 & 5 & 2 & 6.279 & 5.107 & 6.384 & -15.4926 & 5.92333 \\
\hline
\end{tabular}

After analyzing the design of experiments response table for mean and response table for signal to noise ratio were calculated. For the better result smaller is better is selected. Table $3.5 \& 3.6$ shows the response table for mean and signal to noise ratio.

Table 3.5: Response Table for Signal to Noise Ratios (Smaller is Better)

\begin{tabular}{|l|l|l|l|l|}
\hline Level & $\begin{array}{l}\text { Current } \\
\text { (A) }\end{array}$ & $\begin{array}{l}\text { Voltage } \\
(\mathrm{B})\end{array}$ & $\begin{array}{l}\text { Pulse on time } \\
\text { (C) }\end{array}$ & $\begin{array}{l}\text { Pulse off time } \\
(\mathrm{D})\end{array}$ \\
\hline 1 & -7.739 & -10.268 & -9.705 & -9.783 \\
\hline 2 & -7.161 & -9.586 & -10.625 & -9.607 \\
\hline 3 & -14.938 & -9.984 & -9.507 & -10.447 \\
\hline Delta & 7.777 & 0.683 & 1.118 & 0.840 \\
\hline Rank & 1 & 4 & 2 & 3 \\
\hline
\end{tabular}

Table 3.6: Response Table for Mean (Smaller is Better)

\begin{tabular}{|l|l|l|l|l|}
\hline Level & $\begin{array}{l}\text { Current } \\
(\mathrm{A})\end{array}$ & $\begin{array}{l}\text { Voltage } \\
(\mathrm{B})\end{array}$ & $\begin{array}{l}\text { Pulse on time } \\
(\mathrm{C})\end{array}$ & $\begin{array}{l}\text { Pulse off time } \\
(\mathrm{D})\end{array}$ \\
\hline 1 & 2.417 & 3.443 & 3.322 & 3.441 \\
\hline 2 & 2.271 & 3.279 & 3.666 & 3.270 \\
\hline
\end{tabular}


Parameter Optimization of Wire EDM for EN 24 Alloy Steel

\begin{tabular}{|l|l|l|l|l|}
\hline 3 & 5.538 & 3.504 & 3.239 & 3.515 \\
\hline Delta & 3.268 & 0.225 & 0.427 & 0.246 \\
\hline Rank & 1 & 4 & 2 & 3 \\
\hline
\end{tabular}

Table 3.6 shows the major factor which affects the SR. It is clearly shows in the response table for SR that Current is ranked one; Pulse on Time is ranked second, Pulse off time third and voltage is fourth. It means that most predominant factor is Current and other has less impact to the earlier one. Now these values of S/N ratio and Mean are plotted in the shape of a graph which will tell individual parameter and its effect.
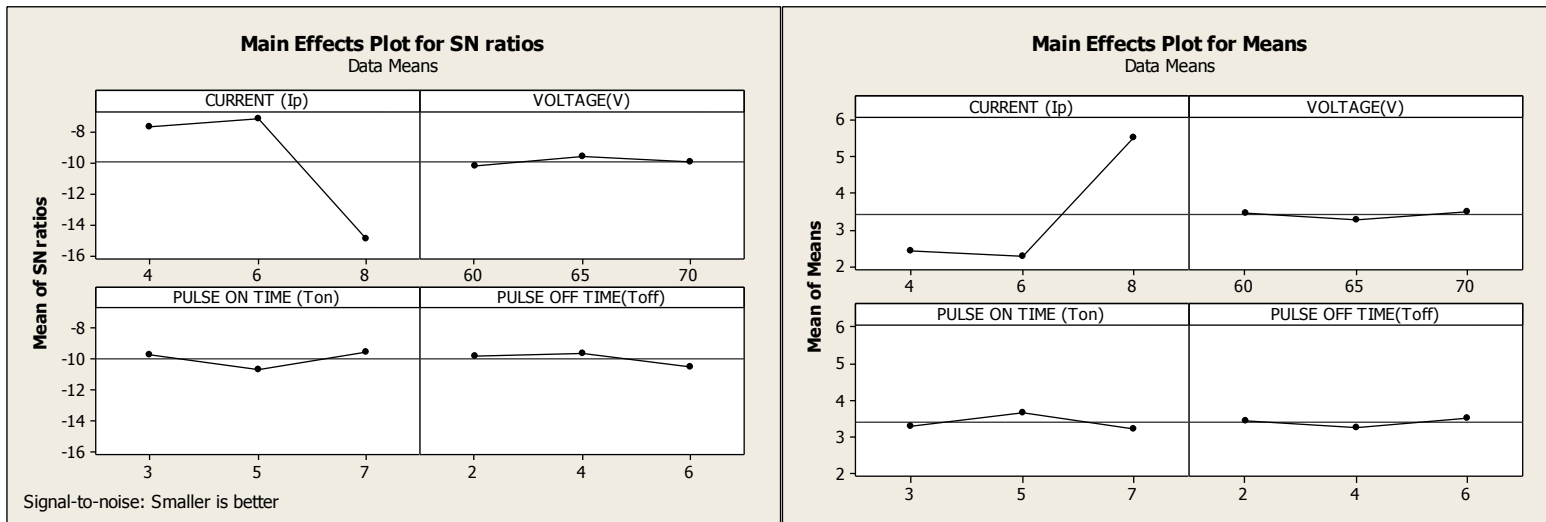

Figure 3.2: main effects plot for mean and $\mathrm{S} / \mathrm{N}$ ratio

It can be seen by the figure 3.2 clearly that the value of surface roughness increases sharply for the Current as their level increases. The discharge energy increases with the pulse on time and peak current and larger discharge energy produces a larger crater, causing a larger surface roughness value on the work piece. The value of voltage and pulse on time first increases and then decreases. The value of Pulse off time first decreases and then increase as their value increases.

\section{Analysis of Variance - MRR}

The results were analyzed using ANOVA for identifying the significant factors affecting the performance measures. The Analysis of Variance (ANOVA) for the mean MRR at 95\% confidence interval is given in Table. The variation data for each factor and their interactions were F-tested to find significance of each calculated by the formula. The principle of the F-test is that the larger the F value for a particular parameter, the greater the effect on the performance characteristic due to the change in that process parameter where $\mathrm{F}$ is the fisher value. ANOVA table shows that current, pulse on time, pulses off time, voltage are the factors that significantly affect the MRR

Table 3.7: ANOVA for S/N Ratio of MRR

\begin{tabular}{|l|l|l|l|l|l|l|}
\hline Source & DF & Seq SS & Adj SS & Adj MS & F & P \\
\hline Current(A) & 1 & 99.542 & 99.542 & 99.542 & 37.57 & 0.004 \\
\hline Voltage(V) & 1 & 1.055 & 1.055 & 1.055 & 0.40 & 0.562 \\
\hline Pon $(\mu \mathrm{s})$ & 1 & 4.610 & 4.610 & 4.610 & 1.74 & 0.258 \\
\hline Poff( $\mu \mathrm{s})$ & 1 & 8.225 & 8.225 & 8.225 & 3.10 & 0.153 \\
\hline Residual error & 4 & 10.598 & 10.598 & 2.650 & & \\
\hline Total & 8 & 124.031 & & & & \\
& & & & & & \\
\hline
\end{tabular}

$\mathrm{S}=1.62776, \mathrm{R}-\mathrm{Sq}=91.46 \%, \mathrm{R}-\mathrm{Sq}(\operatorname{adj})=82.91 \%$

Seq $\mathrm{SS}=$ Sum of squares, $\mathrm{DOF}=$ degree of freedom, Adj $\mathrm{MS}=$ adjusted mean square or variance

** Significant at $95 \%$ confidence level.

In table 3.7 column 1 represents variable sources such as current, voltage, pulse on time, pulse off time and the interactions between these four factors. Subsequently in the following columns degree of freedom (DF), Sum of squares (Seq SS), adjusted mean of square (Adj MS), F distribution and Probability are calculated respectively. The standard deviation of errors in the modeling, $\mathrm{S}=1.62776$. $\mathrm{R}-\mathrm{Sq}=82.91 \%$ which indicates that the model is capable of predicting the response with a high accuracy. 
Table 3.8: ANOVA for Mean of MRR

\begin{tabular}{|l|l|l|l|l|l|l|}
\hline Source & DF & Seq SS & Adj SS & Adj MS & F & P \\
\hline Current(A) & 1 & 0.112067 & 0.112067 & 0.112067 & 35.99 & 0.004 \\
\hline Voltage(V) & 1 & 0.002400 & 0.002400 & 0.002400 & 0.77 & 0.430 \\
\hline Pon $(\mu \mathrm{s})$ & 1 & 0.002817 & 0.002817 & 0.002817 & 0.90 & 0.395 \\
\hline Poff $(\mu \mathrm{s})$ & 1 & 0.004817 & 0.004817 & 0.004817 & 1.55 & 0.282 \\
\hline Residual error & 4 & 0.012456 & 0.012456 & 0.003114 & & \\
\hline Total & 8 & 0.134556 & & & & \\
& & & & & \\
\hline
\end{tabular}

In table 3.8 column 1 represents variable sources such as current, voltage, pulse on time, and pulse off time and the interactions between these four factors. Subsequently in the following columns degree of freedom (DF), Sum of squares (Seq SS), adjusted mean of square (Adj MS), F distribution and Probability are calculated respectively. The standard deviation of errors in the modeling, $\mathrm{S}=0.0558022$. $\mathrm{R}-\mathrm{Sq}=90.74 \%$ which indicates that the model is capable of predicting the response with a high accuracy.

After conducting P-test and F-test for the Anova for MRR, It is find out that the value of $\mathrm{f}$ test in maximum for current and the value of $\mathrm{P}$ is less than 0.05 that means the model is significant

\section{Analysis of variance SR}

The results were analyzed using ANOVA for identifying the significant factors affecting the performance measures. The Analysis of Variance (ANOVA) for the mean SR at 95\% confidence interval is given in table 3.9. The variation data for each factor and their interactions were F-tested to find significance of each calculated by the formula. The principle of the F-test is that the larger the $\mathrm{F}$ value for a particular parameter, the greater the effect on the performance characteristic due to the change in that process parameter. ANOVA table shows that current, pulse on time, pulses off time, voltage are the factors that significantly affect the SR. Current have highest contribution to SR

Table 3.9: ANOVA for S/N Ratio of MRR

\begin{tabular}{|l|l|l|l|l|l|l|}
\hline Source & DF & Seq SS & Adj SS & Adj MS & F & P \\
\hline Current(A) & 1 & 76.746 & 76.746 & 76.746 & 8.17 & 0.046 \\
\hline Voltage(V) & 1 & 0.122 & 0.122 & 0.122 & 0.01 & 0.915 \\
\hline Pon $(\mu \mathrm{s})$ & 1 & 0.059 & 0.059 & 0.059 & 0.01 & 0.941 \\
\hline Poff( $\mu \mathrm{s})$ & 1 & 0.662 & 0.662 & 0.662 & 0.07 & 0.805 \\
\hline Residual error & 4 & 38.083 & 38.083 & 9.521 & & \\
\hline Total & 8 & 116.670 & & & & \\
\hline
\end{tabular}

In table 3.9 column 1 represents variable sources such as current, voltage, pulse on time, pulse off time and the interactions between these four factors. Subsequently in the following columns degree of freedom (DF), Sum of squares (Seq SS), adjusted mean of square (Adj MS), F distribution and Probability are calculated respectively.

The standard deviation of errors in the modeling, $\mathrm{S}=3.08555$. $\mathrm{R}-\mathrm{Sq}=67.36 \%$ which indicates that the model is capable of predicting the response with a high accuracy. 
Table 3.10: ANOVA for Mean of SR

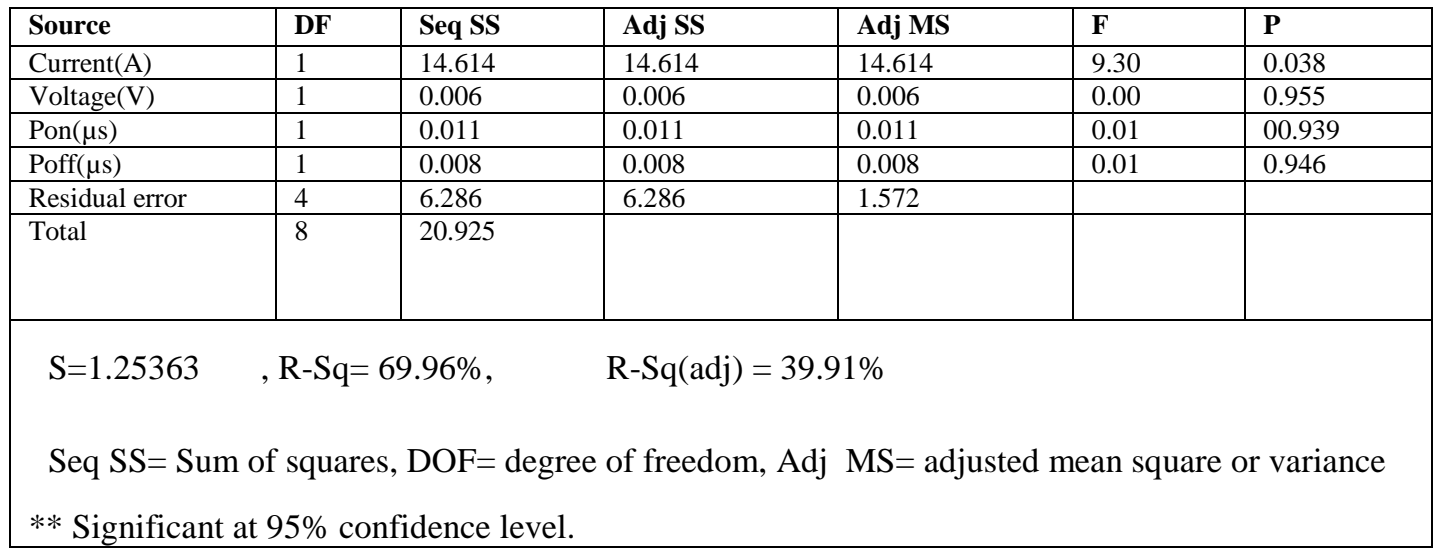

In table 3.10 column 1 represents variable sources such as current, voltage, pulse on time, pulse off time and the interactions between these four factors. Subsequently in the following columns degree of freedom (DF), Sum of squares (Seq SS), adjusted mean of square (Adj MS), F distribution and Probability are calculated respectively. The standard deviation of errors in the modeling, $\mathrm{S}=1.25363$. $\mathrm{R}-\mathrm{Sq}=69.96 \%$ which indicates that the model is capable of predicting the response with a high accuracy.

\section{Conclusion}

In this dissertation, EDM process the effect of current, pulse-on time, pulse off time and voltage has been investigated. The effect of input parameter on output response like Material removal rate and Surface roughness were analyzed for work material En24 Alloy Steel. L9 orthogonal array based on Taguchi design and ANOVA was performed for analyzing the result.

1. The maximum material removal rate is $0.48 \mathrm{~g} / \mathrm{min}$ and it is noted at the value of current $8 \mathrm{~A}$, voltage $70 \mathrm{~V}$, pulse on time $5 \mu \mathrm{s}$ and pulse off time $2 \mu \mathrm{s}$

2. The minimum surface roughness is $2.0036 \mu \mathrm{m}$ and it is noted at the value of current $6 \mathrm{~A}$, voltage $65 \mathrm{~V}$, pulse on time $7 \mu \mathrm{s}$ and pulse off time $2 \mu \mathrm{s}$

3. The most predominant factors for Material removal rate is Current, rest three factors (voltage, pulse on time, pulse off time) has less impact as compare to the current.

4. The value of material removal rate for the current is increasing sharply it mean that material removal rate will increase as the value of current increasing

5. The most predominant factors for Surface roughness is also Current, rest three factors (voltage, pulse on time, pulse off time) has less impact as compare to the current

6. It is concluded that for Maximum Material removal rate the parametric combination is current third (A3), Voltage at second Level (B 2), Pulse on time at level first (C1) and pulse off time at level second (D2) i.e. $8 \mathrm{~A}$ current, $65 \mathrm{~V}$ voltage, $3 \mu$ s pulse on time and $4 \mu$ s pulse off time

7. It is concluded that for Minimum Surface Roughness the parametric combination is current second (A2), Voltage at second Level (B 2), Pulse on time at level third (C3) and pulse off time at level second (D2) i.e. $6 \mathrm{~A}$ current, $65 \mathrm{~V}$ voltage, $7 \mu$ s pulse on time and $4 \mu$ s pulse off time

\section{References}

[1]. K. Rajmohan, A.Senthil Kumar., 2016. "Experimental investigation and prediction of optimum process parameters of micro-wirecut EDM of 2205 DSS", Int J Adv Manuf Technol DOI 10.1007/s00170-016-8615-3.

[2]. Muhammad Azam , Mirza Jahanzaib, Junaid Ali Abbasi, Musharaf Abbas Ahmad Wasim, Salman Hussain., 2016. "Parametric analysis of recast layer formation in wire-cut EDM of HSLA steel", Int J Adv Manuf Technol, DOI 10.1007/s00170-016-8518-3.

[3]. Hongzheng Liu, Zhenlong Wang, Yukui Wang, Huichao Li, 2016. "Self-induced electrical discharge machining of Ni-Al2O3 functionally graded materials", Int J Adv Manuf Technol (2016) 83:587-594 DOI 10.1007/s00170-015-7568-2

[4]. Mohammad Reza Shabgard, Ahad Gholipoor, Hamid Baseri, , 2016. "A review on recent developments in machining methods based on electrical discharge phenomena", Int J Adv Manuf Technol DOI 10.1007/s00170-016-8554-Z

[5]. Mu-Tian Yan, Pi-Wen Wang, Jian-Cheng Lai, , 2016. "Improvement of part straightness accuracy in rough cutting of wire EDM through a mechatronic system design”, Int J Adv Manuf Technol (2016) 84:2623-2635 DOI 10.1007/s00170-015-7908-2

[6]. Mychal-Drew Moses, M. P. Jahan, 2015. "Micro-EDM machinability of difficult-to-cut Ti-6Al-4V against soft brass", Int J Adv Manuf Technol (2015) 81:1345-1361 DOI 0.1007/s00170-015-7306-9

[7]. Tanveer Saleh, Aous Naji Rasheed, Asan G. A. Muthalif, 2015. "Experimental study on improving $\mu$-WEDM and $\mu$-EDM of doped silicon by temporary metallic coating", Int J Adv Manuf Technol (2015) 78:1651-1663 DOI 10.1007/s00170-014-6732-4

[8]. Vivek Aggarwal, Sehijpal Singh Khangura. R. K. Garg, 2015. "Parametric modeling and optimization for wire electrical discharge machining of Inconel 718 using response surface methodology", Int J Adv Manuf Technol (2015) 79:31-47 DOI 10.1007/s00170015-6797-8. 
[9]. Ibrahem Maher \& Ahmed A. D. Sarhan \& M. Hamdi, 2015 “ Review of improvements in wire electrode properties for longer working time and utilization in wire EDM machining”, Int J Adv Manuf Technol (2015) 76:329-351DOI 10.1007/s00170-0146243-3

[10]. Hamid Abyar Firouzabadi, Jamshid Parvizian, Amir Abdullah, 2015 “ Improving accuracy of curved corners in wire EDM successive cutting", Int J Adv Manuf Technol (2015) 76:447-459 DOI 10.1007/s00170-014-6270-0

[11]. A. Varun, Nasina Venkaiah., 2014. "Simultaneous optimization of WEDM responses using grey relational analysis coupled with genetic algorithm while machining EN 353", Int J Adv Manuf Technol 76:675-690 DOI 10.1007/s00170-014-6198-4

[12]. Dhirendra nath mishra , Aarti Bhatia , Vaibhav rana, 2014 “ Study on Electro Discharge Machining (Edm”, The International Journal Of Engineering And Science (IJES), Volume3, Issue 2, Pages24-35,2014 ISSN(e): 2319 - 1813 ISSN(p): 2319 - 1805

[13]. R. Bagherian Azhiri, R. Teimouri , M. Ghasemi Baboly, Z. Leseman, 2014. "Application of Taguchi, ANFIS and grey relational analysis for studying, modeling and optimization of wire EDM process while using gaseous media", Int J Adv Manuf Technol (2014) 71:279-295 DOI 10.1007/s00170-013-5467-y

[14]. G. Rajyalakshmi , P. Venkata Ramaiah, 2013. "Multiple process parameter optimization of wire electrical discharge machining on Inconel 825 using Taguchi grey relational analysis", Int J Adv Manuf Technol (2013) 69:1249-1262 DOI 10.1007/s00170-0135081-z

[15]. Anish Kumar, Vinod Kumar, Jatinder Kumar, 2013. "Multi-response optimization of process parameters based on response surface methodology for pure titanium using WEDM process", Int J Adv Manuf Technol (2013) 68:2645-2668 DOI 10.1007/s00170-0134861-9

[16]. Samar Singh, MukeshVerma, 2012. "A Parametric Optimization of Electric Discharge Drill Machine Using Taguchi Approach", Journal of Engineering, Computers \& Applied Sciences (JEC\&AS) ISSN No: 2319-5606 Volume 1, No.3, December 2012

[17]. jin woo park,Do kwan chung, Bo hyun kim, Jog girl ok, Wal jun kim, Yong hyup kim and Chong nam chu ,2012 . "Wire electrical discharge machining of carbon nanofiber mats for field emission", international journal of precision engineering and manufacturing vol. 13, no. 4, pp. 593-599, april 2012

[18]. Rong Tai Yang, Chorng Jyh Tzeng, Yung Kuang Yang, Ming Hua Hsieh, 2012. "Optimization of wire electrical discharge machining process parameters for cutting tungsten”, Int J Adv Manuf Technol (2012) 60:135-147 DOI 10.1007/s00170-011-3576-Z

[19]. Singh, H., (2012), Experimental study of distribution of energy during EDM process for utilization in thermal models', International Journal of Heat and Mass Transfer, Vol.55, pp.5053-5064.

[20]. Senthil, K.V. and Omparkash, B.U. (2011), "Effect of Titanium carbide particle addition in aluminum composite on EDM process parameters", Journal of Materials Processing Technology, Vol. 13, pp. 60-66.

[21]. Narcis Pellicer · Joaquim Ciurana · Jordi Delgado, 2009. "Tool electrode geometry and process parameters influence on different feature geometry and surface quality in electrical discharge machining of AISI H13 steel", J Intell Manuf 22:575-584 DOI 10.1007/s10845-009-0320-8.

[22]. Amin, N., Lajis, M.A. and Radzi, M. (2009), "The Implementation of Taguchi Method on EDM Process of Tungsten Carbide", European Journal of Scientific Research, Vol. 26, No. 4, pp. 609-617.

[23]. Hewidy MS, El-Taweel TA, El-Safty MF (2005), "Modeling the machining parameters of wire electrical discharge machining of Inconel 601 using RSM". J Mater Process Technol 169:328-336

[24]. Singh, S., Maheswari, S. and Pandey, P.C. (2004), "Some investigation into the Electric discharge machining of hardened tool steel using different electrode materials", Journal of Materials Processing Technology, Vol. 149, pp. 272-277. 